\title{
Monitoring the Effect of Pyrene on the Germination and Radial Growth of the Wild and Mutant Strains of Rhizopus arrhizus UCP402
}

\author{
Ricardo Kenji Shiosaki ${ }^{1}$, Clarissa Daisy da Costa Albuquerque ${ }^{1,3}$, Kaoru Okada ${ }^{1,2}$, \\ Kazutaka Fukushima ${ }^{5}$ and Galba Maria Campos-Takaki ${ }^{1,4^{*}}$ \\ ${ }^{1}$ Núcleo de Pesquisas em Ciências Ambientais; ${ }^{2}$ Departamento de Biologia; ${ }^{3}$ Departamento de Estatística e \\ Informática; ${ }^{4}$ Departamento de Química; Universidade Católica de Pernambuco; 50050-590; Recife - PE - Brazil. \\ ${ }^{5}$ Research Center for Pathogenic Fungi and Microbial Toxicoses, Chiba University, Inohana 1-8-1, Chuo-ku, Chiba \\ 260-8673, Japan
}

\begin{abstract}
The physiological mutant of Rhizopus arrhizus was obtained in the pyrene resistance gradient test. Comparative studies were carried out about the behavior of the germination process and the radial growth of the mutant and wild strains of R. arrhizus UCP 402. Sabouraud Sucrose and Yeast Malt Broth cultures containing pyrene (10 mg/L) induced the germination process of the sporangiospores of the wild and mutant strains of R. arrhizus. The radial growth of the strains was inversely proportional to the pyrene concentration in the culture medium. The results showed an adaptation of R. arrhizus UCP 402x (mutant) in the pyrene $(50 \mathrm{mg} / \mathrm{L})$ and suggested a higher ability of application in the removal of pyrene from the contaminated areas.
\end{abstract}

Key words: Pyrene, Rhizopus arrhizus, mutant, radial growth, germination

\section{INTRODUCTION}

The toxic residues have been taking a place of prominence in the society and when inadequately managed are harmful to the environment and also cause damages to the public health. There are many industrial processes as well as accidents from the usage and the transportation of the oil (Uygur, 2001; Valle, 1995) that pose polluting potential. Taking in to account that the contamination by the recalcitrant substances as the Polycyclic Aromatic Hydrocarbon (PAH's) by the natural or anthropogenic sources become evident in the environment and that many of them have shown carcinogenic, mutagenic and teratogenic nature, as well as toxic effects to the living organisms (Lijinsky et al., 1963; Ravelet et al., 2000), the utilization of the methodologies using the fungi and bacteria have displayed the importance of these organisms in the process of the decontamination of the polluted area, showing a relatively low cost and significant results ( $\mathrm{Fu}$ and Viraraghavan, 2001). On the other hand, studies have been made with the objective of removing the toxic compounds from the environment, and obtaining resistant mutants due to the promising results in the processes of removal of these compounds (Alexievaa et al., 2004; England et al., 1998; Lijinsky et al., 1963; Mc Cullar et al., 2002; Oda and Ohta, 2002).

${ }^{*}$ Author for correspondence 
Recent studies demonstrated a greater capacity of phenol degradation by the mutant strains of Trichosporon cutaneum when compared to the wild strains (Alexievaa et al., 2004). The Phanerochaete chrysosporium mutants obtained from UV lights, allowed some species to increase their ability of lignin degradation (Kirk and Tien, 1986). In this paper, we report the isolation of a mutant of $R$. arrhizus UCP 402 in high concentrations of pyrene and the accomplishment of comparative studies with the wild and mutant strains, aiming to establish the physiological characteristics and pyrene adaptation conditions.

\section{MATERIALS AND METHODS}

Microorganism: Rhizopus arrhizus UCP 402, was isolated from the mangrove sediment of Rio Formoso, Pernambuco, Brazil (Gomes et al., 2000). The strain was maintained on PDA medium and stored at $5^{\circ} \mathrm{C}$, and deposited in the Culture Collection UCP of Universidade Católica de Pernambuco (UNICAP).

\section{Polycyclic Aromatic Hydrocarbon}

The stock solution was prepared dissolving the pyrene (WAKO) in acetone at $2 \mathrm{~g} / \mathrm{L}$ concentration, filtered by Millipore $0.45 \mu \mathrm{m}$ membrane, and kept in amber flasks at $5^{0} \mathrm{C}$.

\section{Gradient test of pyrene resistance}

Petri dishes of $9 \mathrm{~cm}$ diameter were used and incorporated with the Potato Dextrose Agar (PDA) ( $\mathrm{pH}$ 5.8) containing pyrene at the final concentration of $100 \mathrm{mg} / \mathrm{L}$ and solidified in an inclined shape so that one side had $1.6 \mathrm{~mm}$ of height. After the solidification, $9 \mathrm{~mL}$ of the same medium (without pyrene) was added and left to solidify in a horizontal surface (Maas, 1986). The spores were removed from cultures (Potato Dextrose Agar Medium) and transferred to the assay tubes containing $10 \mathrm{~mL}$ of sterile distilled water and counted in a Neubauer chamber. $1 \mathrm{~mL}$ of the suspension containing $10^{3}$ spores of $R$. arrhizus UCP402 was inoculated in the Petri dish containing a pyrene concentration gradient, incubated in the dark at $28^{\circ} \mathrm{C}$ for $72 \mathrm{~h}$. After the colonies growth, they were removed from two areas of distinct concentration, without pyrene and the highest pyrene concentration. The colony proceeding from the highest pyrene concentration region (mutant strain $R$. arrhizus UCP402x) was transferred from the Petri dishes containing the PDA medium and pyrene in $5 \mathrm{mg} / \mathrm{L}$ concentration. The colony from the region without the pyrene was removed and kept in Petri dishes containing only PDA, corresponding to the wild strain of $R$. arrhizus UCP 402.

Germination of R. arrhizus UCP402 and R. arrhizus UCP402x (mutant) sporangiospores

The $R$. arrhizus UCP 402 and $R$. arrhizus UCP $402 x$ (mutant) sporangiospores germination was performed in Erlenmeyer flasks of $125 \mathrm{~mL}$, containing $10 \mathrm{~mL}$ of Yeast Malt Broth (YMB) and Sabouraud Sucrose (SAC) as the control and treated with pyrene at the final concentration of $10 \mathrm{mg} / \mathrm{L}$ (Ambrosio, 2002). The flask were inoculated with $1 \mathrm{~mL}$ of the spores suspension $(1.4$ x $10^{8}$ spores $/ \mathrm{mL}$ ) of $R$. arrhizus UCP402 and $R$. arrhizus UCP402x (mutant), incubated at $28^{\circ} \mathrm{C}$ in a shaker at $140 \mathrm{rpm}$. The germination was observed using $40 \mu \mathrm{L}$ of the harvested aliquots each 30 minutes rate during $6 \mathrm{~h}$. After this, the aliquots were visualized in an optical microscope with an $\times 40$ objective to detect the presence of the germinating tubes, (a total of 200 spores of each sample). The experiments were made in triplicate (Robinson, 1978).

Radial growth of R. arrhizus UCP402 and R. arrhizus UCP402x (mutant) in the culture mediums PDA, SAC and YMA

$R$. arrhizus UCP402 wild and $R$. arrhizus UCP402x (mutant) was grown for 48h in the PDA medium. The disks ( $5 \mathrm{~mm}$ diameter) were removed aseptically from the periphery of each colony and transferred to Petri dishes containing $20 \mathrm{~mL}$ of the PDA, YMB and SAC media with pyrene (10 and $50 \mathrm{mg} / \mathrm{L}$ ), and without pyrene (control). The Petri dishes were incubated at $28^{\circ} \mathrm{C}$ in the absence of light. The radial growth was daily measured with the help of a scale and determined the diameters of the colony along with two perpendicular axes over the time. The readings were made in $6 \mathrm{~h}$ intervals up to a total period of $48 \mathrm{~h}$. The growth curve was constructed based on the averages of the values (Millner, 1977).

\section{Statistical analysis}

To evaluate the influence of the pyrene concentrations under the germination of sporangiospores and radial growth of $R$. arrhizus 
UCP402 and $R$. arrhizus UCP402x (mutant) grown in the three tests culture mediums (PDA, YMB and SAC), the data obtained were submitted to the variance analysis (ANOVA).

\section{RESULTS AND DISCUSSION}

Evaluation of the sporangiospores germination of R. arrhizus UCP402 and R. arrhizus UCP402x in the YMB culture medium

The sporangiospores germination of $R$. arrhizus UCP402 and R. arrhizus UCP402x (mutant) in the YMB culture medium containing $10 \mathrm{mg} / \mathrm{L}$ of pyrene and the control is presented in Fig. 1. It was observed that the sporangiospores of the wild and mutant $R$. arrhizus strains began the emission of germination $2 \mathrm{~h}$ after the inoculation in YMB medium. After $6 \mathrm{~h}$, all the spores showed the germination. These results were corroborated by the others authors also, (Ekundayo and Carlile, 1964; Hawker and Abbott, 1963). On the other hand, the spores of the wild $R$. arrhizus $\mathrm{UCP} 402$ and $R$. arrhizus

UCP402x (mutant) were incubated in SAC culture medium, the germination began $3: 30 \mathrm{~h}$ after the inoculation, later than the YMB medium (Fig. 2). The germination and a linear raise in the diameter from 7.6 to $9.8 \mu \mathrm{m}$ after $4 \mathrm{~h}$ of incubation at $25^{\circ} \mathrm{C}$ in sporangiospores of Rhizopus stolonifer has been described by many authors, (Ekundayo and Carlile, 1964; Fletcher, 1969; Trinci, 1971). The multipolar germination pattern was observed in the spores of both the strains of $R$. arrhizus (mutant and wild) in the YMB and SAC control and treated culture media. It was also observed that the YMB and SAC culture media, when the strains were submitted to the pyrene treatment, accelered the germination, when compared to the control (medium without pyrene).
A

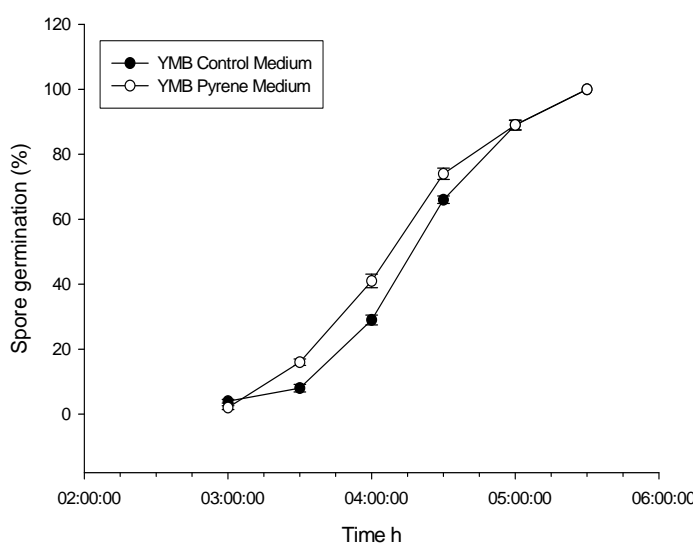

B

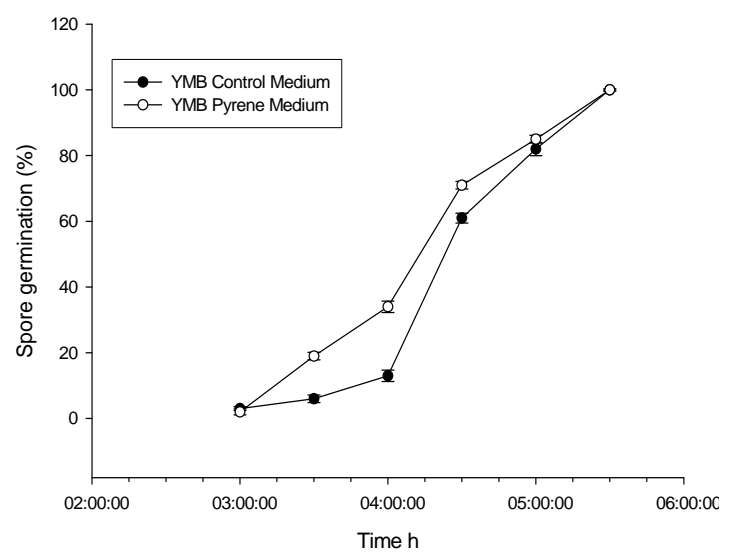

Figure 1 - Germination of Rhizopus arrhizus UCP402(A) and R. arrhizus UCP 402x (B) in Yeast Malt Broth (YMB) control and treated with pyrene medium $(10 \mathrm{mg} / \mathrm{L})$, at $28^{\circ} \mathrm{C}$. 
$\mathbf{A}$

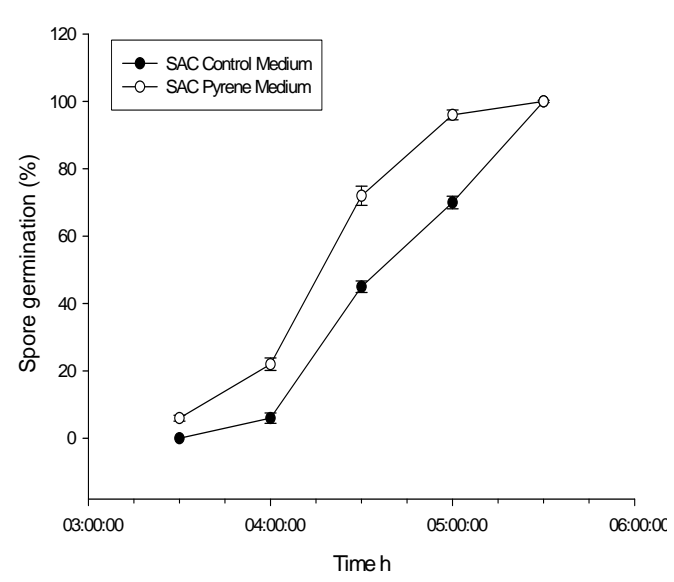

B

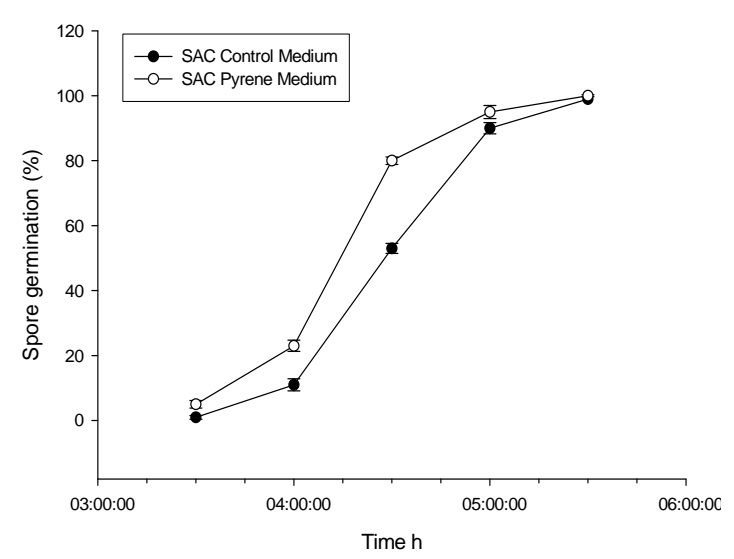

Figure 2 - Germination of Rhizopus arrhizus UCP402 (A) and R. arrhizus UCP 402x (B) in Sabouraud Sucrose (SAC) control and treatead with pyrene medium $(10 \mathrm{mg} / \mathrm{L})$, at $28^{\circ} \mathrm{C}$

These results suggested that the mechanism of accelerating the germination process by pyrene was promoted by the changes of the permeability of the cellular membrane. However, the lack of information in the literature about the germination of the fungal spores in the presence of polycyclic aromatic hydrocarbons, can't allow the comparison of the data obtained. The literature showed that the pesticide 2,4-D, in concentrations of 50, 25, and $13 \%$ stimulated the sporulation of Cercospora rodmanii (Charudattan, 1986). In the studies with the herbicides was also found a significant increase of the number of sporangia of Phytophthora cinnamomi with the addition of propazine and simazine (Kassaby and Hepworth, 1987). Some investigations attributed these phenomena to a mechanism of the defense, once that those compounds strongly inhibited the radial growth, and the pesticides showed the effect on the germination suppression (Malajeczuk et al., 1983; Marks and Smith, 1983; Uribe et al., 1990).

\section{Radial growth of $\mathrm{R}$ arrhizus UCP402 and $\mathrm{R}$. arrhizus UCP402x (mutant) in the PDA, YMB and SAC media}

The statistically treatment (ANOVA) of the effect of the pyrene on the radial growth showed in a $5 \%$ significance level. The results confirmed that the presence of the pyrene significantly affected the radial growth of the strains of $R$. arrhizus $\mathrm{UCP} 402$ and $R$. arrhizus UCP402x (mutant) in the PDA, YMB and SAC culture media. The results of $F$ were higher than the tabulated values (Figs. 3-5). The growth of the two strains of $R$. arrhizus was inversely proportional to the concentration of the pyrene in all the culture media. 
A

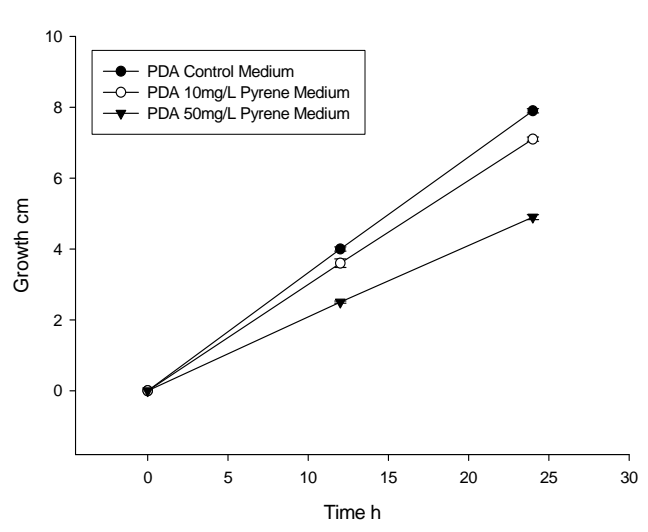

B

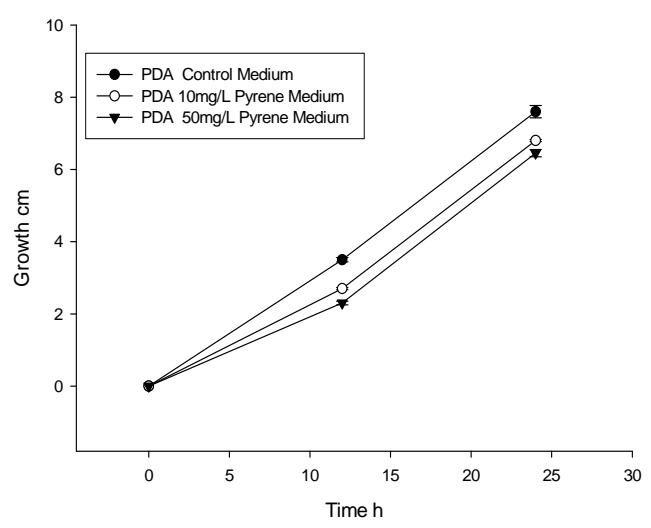

Figure 3 - Radial growth of Rhizopus arrhizus UCP402 (A) and R. arrhizus UCP 402x (B) in Potato Dextrose Agar (PDA) control and treatead with pyrene $(10 \mathrm{mg} / \mathrm{L})$, at $28^{\circ} \mathrm{C}$

However, the utilization of sucrose in the SAC culture medium showed a even greater reduction in the radial growth both in control and treated medium (Fig. 4). The results did not show the presence of the growth zones, changes in the size of the spores or the sporangium morphology in $R$. arrhizus UCP402 and $R$. arrhizus UCP402x (mutant), when grown in the PDA medium. The studies about the radial growth and pathogenicity in Fusarium moniliforme var. subglutinans isolated revealed that the strains when grown in the Potato Dextrose Agar medium showed a higher radial growth than the strains when grown in Potato Sucrose Agar (Bolkan et al., 1980). The sucrose is a disaccharide whose molecule produces glucose and fructose by the invertase action (Atkins, 2002). These mechanisms were found during the metabolism of the sucrose by the fungi. The production of the invertase was observed in Saccharomyces cerevisiae, S. carlsbergensis and Aspergillus athecius (Baker, 1975; Madyastha et al., 1987).
$\mathbf{A}$

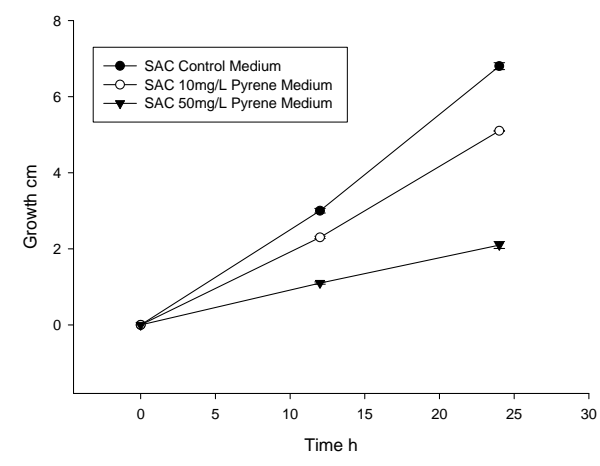

B

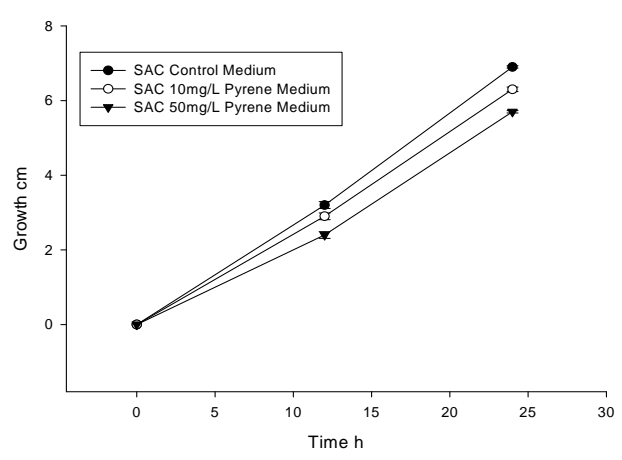

Figure 4 - Radial growth of Rhizopus arrhizus UCP402 (A) and R. arrhizus UCP 402x (B) in Sabouraud Sucrose (SAC) and treated with pyrene $(10 \mathrm{mg} / \mathrm{L})$, at $28^{\circ} \mathrm{C}$ 
A

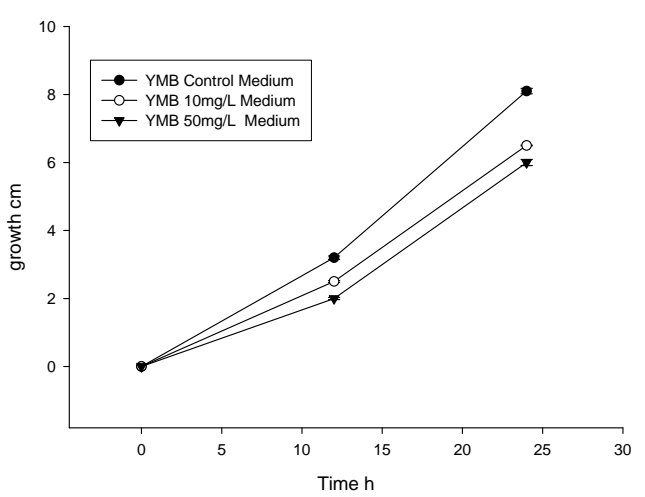

B

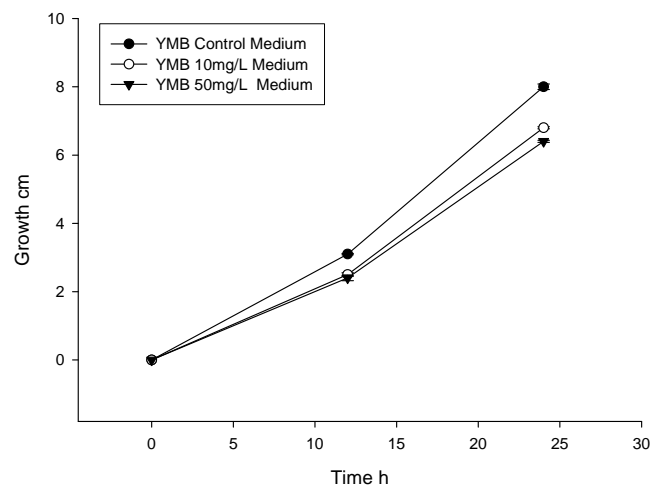

Figure 5 - Radial growth of Rhizopus arrhizus UCP402 (A) and R. arrhizus UCP 402x (B) in Yeast Malt Broth (YMB) control and treatead with pyrene $(10 \mathrm{mg} / \mathrm{L})$, at $28^{\circ} \mathrm{C}$

The glucose molecule is very different, in solution; its energy is immediately available to answer any requests made by a metabolic process, (Atkins, 2002). The analysis obtained from ANOVA showed that statistically the $R$. arrhizus UCP $402 \mathrm{x}$ mutant strain when compared to the wild $R$. arrhizus UCP 402, had a greater ability to grow in high pyrene concentrations $(50 \mathrm{mg} / \mathrm{L})$ in the three tested media. The growth inhibition was also demonstrated when Pseudomonas putida was inoculated in the medium containing glucose as the carbon source and octanol as toxically agent in the $0.6,1.2,1.8$, and $2.4 \mathrm{mM}$ concentration, being inversely proportional to the octanol concentration in the medium (Heipieper et al., 1995). The same result was displayed when Mycromycetes fungi grown in the presence of fluoranthene in the concentrations of $0.001,0.01$ and $0.1 \mathrm{~g} / \mathrm{L}$, showing a decrease in the mycelia growth as the concentration of the toxically compound was increased in the culture medium. Moreover, other effect as the appearance of the sterile mycelia and discolorations of the colonies was observed in some species (Salicis et al., 1999).

A study with the antracene indicated that $95 \%$ of the strains showed high growth rates at $0.1 \mathrm{~g} / \mathrm{L}$ concentration of antracene. However, the growth of Doratomyces stemonitis and Cylindrocarpon destructans were inhibited in concentrations lower than $0.01 \mathrm{~g} / \mathrm{L}$, and Sporormiella australis and Sporothrix cyanescens were strongly inhibited at 0.1 and $1 \mathrm{~g} / \mathrm{L}$ (Krivobok et al., 1998). The diameter of the colony and the radial growth are frequently used to determine the optimal temperature (Brancato and Golding, 1953), as well as to investigate the effect of the inhibitors on the fungal growth (Trinci, 1971). Studies with the radial growth in response to different temperatures can also be used as a base to the morphological studies and taxonomical relations between Chaetomium species (Millner, 1977). The phytopatogenic fungi such as Fusarium oxysporum, Phytophthora megasperma, Phytophthora parasitica and Pythium ultimum showed reduced radial growth rates when cultivated in the presence of the chloroneb, $\mathrm{HgCl}_{2}$, maneb and carboxin, respectively (Tu, 1982). It was suggested that the pesticides like metiram, betertanol and diclorluanide strongly inhibited the mycelia growth of Verticillium lecanii (Khalil et al., 1985). The culture media containing glyfosate, simazine and propazine in recommended concentrations for the field applications significantly inhibited the radial growth of $P$. cinnamomi, reducing to $11.4,13.5$ and $50.2 \%$ when compared to the control (Kassaby and Hepworth, 1987). Studies with azo reactive, another important group of environmental polluants, showed that the increase of the dyes concentration in the culture medium was proportional to the inhibition of the growth of Saccharomyces cerevisiae and Candida tropicalis (Aksu, 2003; Donmez, 2002). A reduction in the mycelial growth was observed, when the fungi grew in the presence of trifenilmethane. The nucleic acids 
contents in the lag and stationary phases was determined. In the lag phase a decrease in the RNA content was observed. This decrease provoked an inhibition of the protein syntesis, which might have caused the reduction in the mycelial growth (Azmi et al., 1988). In studies whose objective was the understanding of the solvents tolerance mechanisms in the bacteria, it was shown that the toluene destabilized the internal membrane of Gram-negatives, causing a transition from a bilayer lamellar state to a hexagonal state, resulting in the loss of the proteins, lipids, ions and the disruption of potential of the cellular membrane (De Smet et al., 1978; Sikkema et al., 1995). The following collapse in the ATP synthesis, with other lesions, caused the cellular death. The interaction of the cyclic hydrocarbons, as the aromatics, alicyclic and terpenes with the biological membranes have already been documented (De Smet et al., 1978; Sikkema et al., 1992; Uribe et al., 1985; Uribe et al., 1990). Those interactions cause the structural, permeability and functional changes in the membranes, which in turn can interrupt the growth and the activities of the cells. Studies with the tetralin in the structure and in the functioning of the liposome membranes in the bacteria showed that the accumulation of this aromatic hydrocarbon in the membrane caused the expansion of the surface area of the membrane, inhibiting the primary ions bomb and the increase in the protons permeability. As a result, the electrical potential and the $\mathrm{pH}$ gradient were dissipated. The authors suggested that those factors constituted the primary cause of the cellular growth inhibition (Sikkema et al., 1992). Studies with other aromatic and alicyclic hydrocarbons indicated that the observed effects were not specific to the tetralin and that a direct relationship can be found between the partitioning of a particular compound in the membrane and its effect in the structural integrity and functional properties of this structure (Sikkema et al., 1994). Some studies displayed the reduction in the cellular growth due to the presence of toxic compounds such as the aromatic hydrocarbons, pesticides and azodyes. However, the physiological mechanisms of the fungal growth inhibition in the presence of PAH is probably a particular effect on the structural integrity and functional properties of the cellular membrane.

\section{ACKNOWLEDGMENTS}

The authors are grateful to the financial agencies FACEPE, CNPq, CNPq/CTPETRO, FINEP.

\section{RESUMO}

O mutante fisiológico de Rhizopus arrhizus foi obtido pelo teste do gradiente de resistência ao pireno. Estudos comparativos conduzidos sobre o comportamento do processo de germinação e o crescimento radial foram realizados entre as amostras selvagem e mutante de $R$. arrhizus UCP 402. Os meios Sabouraud Sacarose e Caldo de Levedura e Malte contendo pireno (10 mg/L) induziram ao processo de germinação de esporangiosporos das amostras selvagem e mutante de $R$. arrhizus. $\mathrm{O}$ crescimento radial das amostras foi inversamente proporcional à concentração de pireno no meio de cultura. Os resultados demonstraram uma excelente adaptação da amostra mutante de $R$. arrhizus UCP 402x na concentração de pireno (50 $\mathrm{mg} / \mathrm{L}$ ), sugerindo uma alta habilidade e possibilidade de aplicação na remoção de pireno em áreas contaminadas.

\section{REFERENCES}

Alexievaa, Z., Gerginova, M., Zlateva, P., Peneva, N. (2004), Comparison of growth kinetics and phenol metabolizing enzymes of Trichosporon cutaneum R57 and mutants with modified degradation abilities. Enzyme Microbial Technol, 34, 3-4, 242-247.

Ambrosio, S. T. (2002), Remoção de corantes utilizados em indústria têxtil por Cunninghamella elegans UCP542. Tese de Doutorado. Universidade Federal de Pernambuco, PE, Brasil.

Aksu, Z. (2003), Reactive dye bioaccumulation by Saccharomyces cerevisiae. Process Biochem., 38, 14371444.

Atkins, P. W. Moléculas. (2002), Ed. da Universidade de São Paulo. SP. 198p.

Azmi, w., Kumar, R. S., Banerjee, U. C. (1988), Biodegradation of triphenylmethane dyes. Enzyme Microbial Technol., 22, 185-191.

Baker, S. A. (1975), High fructose syrups, new sweeteners in the food industry. Process Biochem., 10, 39-40.

Bolkan, H. A., Dianese, J. C., Wilma, R. C. Ribeiro, da Silva, C. B. (1980), Relationship between cultural characteristics and pathogenicity in Fusarium moniliforme var. Subglutinans. Fitopatol. Brás., 5, 265271. 
Brancato, F. P., Golding, N. S.(1953), The diameter of the mold colony as a reliable measure of growth. Mycologia, 45, 848-864.

Charudattan, R. (1986), Integrated control of waterhyacinth (Eichhornia crassipes) with a pathogen, insects and hebicides. Weed Sci., 34, 2630.

De Smet, M. J., Kingma, J., Witholt, B. (1978), The effect of toluene on the structure and permeability of the outer and cytoplasmic membranes of Escherichia coli. Biochi. Biophys Acta, 506, 64-80.

Donmez, G. (2002), Bioaccumulation of the reactive textile dyes by Candida tropicalis growing in molasses medium. Enzyme Microbial Technol., 30, 363-366.

Ekundayo, J. A., Carlile, M. J. (1964), The germination of sporangiospores of Rhizopus arrhizus; spore swelling and germ-tube emergence. J. Gen. Microbiol., 35, 261.

England, P. A., Harford-Cross, F., Stevenson, J. A. Rouch, D. A., Wong, L. L. (1998), The oxidation of naphthalene and pyrene by cytochrome $\mathrm{P} 450_{\text {cam }}$. FEBS Letters, 424, 271-274.

Fletcher, J. (1969), Morphology and nuclear behaviour of germinating conidia of Penicillium griseofulvum. Trans. Brit. Mycol. Soc., 53, 425432.

Fu, Y., Viraraghavan, T. (2001), Fungal decolorization of dye wastewaters: a review. Bioresouce Technol., 79, 251-262.

Gomes, P. F., Nascimento, A. E., Okada, K., Messias, A. S., Sharia, A. E. N., Campos-Takaki, G. M. (2000), Aspectos da qualidade de ecossistemas do Município do Rio Formoso. International Conference-Sustainable use of stuaries and mangroves: challenges and prospects, p.82.

Hawker, L. E., Abbott, P. M. V. (1963), Fine structure of vegetative hyphae of Rhizopus. J. Gen. Microbiol., 30, 401.

Heipieper, H. J., Loffeld, B., Keweloh, H., De Bont, J. A. M. (1995), The cis/trans isomerisation of unsaturated fatty acids in Pseudomonas putida s12: an indicator for environmental stress due to organic compounds. Chemosphere, 30, 1041-1051.

Kassaby, F. Y., Hepworth, G. (1987), Phytophthora cinnamomi: Effects of herbicides on radial growth, sporangial production, inoculum potential and root disease in Pinus radiata. Soil Biol. and Biochem., 19, 4, 437-441.

Khalil, S. K., Shah, M. A., Naeem, M. (1985), Laboratory studies on the compatibility of the entomopathogenic fungus Verticillium lecanii with certain pesticides. Agric., Ecosystems Environ., 13, 329-334.
Kirk, T. K., Tien, M. (1986), Lignin degrading activity of Phanerochaete chrysosporium burds: comparison of cellulase-negative and other strains. Enzyme Microbial Techno., 8, 75-80.

Krivobok, S., Miriouchkine, E., Seigle-Murandi, F., Benoit-Guyod, J. L. (1998), Biodegradation of Anthracene by Soil Fungi. Chemosphere, 37, 3, 523530.

Lijinsky, W., Domsky, I., Mason, G., Rmahi, H. Y., Safavi, T. (1963), The Chromatografic determination of trace amounts of polynuclear hydrocarbons in petroleum, mineral oil, and coal tar. Analytical chemistry, 35, 952-956.

Maas, W. K. (1986), Mutations to antibiotic resistance in Lorian, Victor (ed) Antibiotics in laboratory medicine. Willian e Wilkins, USA, 669-682.

Madyastha, K. M., Ganguli, A. R., Kubair, V. G., Kowser, N., Vidya, D. (1987), Extracellular invertase from Aspergillus athecius: isolation and immobilization. Biotechnol. Letters, 9, 8, 555-560.

Malajeczuk, N., Sanfelieu, C. L., Hossen, S. (1983), Production and survival of Phytophthora cinnamomi zoospores in suppressive and conductive soil. Trans. Brit. Mycol. Society, 80, 305-312.

Marks, G. C., Smith, I. W. (1983), Development of Phytophthora cinnamomi infection in roots of Eucalyptus species growing in a soil that suppresses Phytophthora root disease. Australian J. Botany, 31, 239-45.

Mc Cullar, M. V., Koh, S. C., Focht, D. D. (2002), The use of mutants to discern the degradation pathway of 3,4'-dicholorobiphenyl in Pseudomonas acidovorans M3GY. FEMS Microbiol. Ecol., 42, 81-87.

Millner, P. D. (1977), Radial growth responses to temperature by 58 Chaetomium species, and some taxonomic relationships. Mycologia, 69, 492-502.

Oda, S., Ohta, H. (2002), Biodesulfurization of Dibenzothiophene with Rhodococcus erythropolis ATCC53968 and its mutant in an interface bioreactor. J. Bioscience and Bioenginee., 94, 5, 474-477.

Ravelet, C., Krivobok, S., Sage, L., Steiman, R. (2000) Biodegradation of pyrene by sediment fungi. Chemosphere, 40, 557-563.

Robinson, P. M. (1978), Practical fungal physiology. John Wiley and Sons, p.122.

Salicis, F., Krivobok, S., Jack, M., Benoit-Guyod, J. L. (1999), Biodegradation of Fluoranthene by soil fungi. Chemosphere, 38, 13, 3031-3039.

Sikkema, J., De Bont, J. A. M., Poolman, B. (1994), Interactions of cyclic hydrocarbons with biological membranes. J. Biological Chemistry, 269, 8022-8028.

Sikkema, J., De Bont, J. A. M., Poolman, B. (1995), Mechanisms of membrane toxicity of hydrocarbons. Microbiol. Review, 59, 201-222.

Sikkema, J., Poolman, B., Konings, W. N., De Bont, J. A. M (1992), Effects of the membrane action of tetralin on the functional and structural properties of artificial and bacterial membranes. J. Bacteriol., 174, 2986-2992. 
Trinci, A. P. J. (1971), Influence of the width of the peripheral growth zone on the radial growth rate of fungal colonies on solid media. J. Gen. Microbiol., 67, 325-344.

Tu, C. M. (1982), Effects of some pesticides on Rhizobium japonicus and on the seed germination and pathogens of soybean. Chemosphere, 11, 10, 1027-1033.

Uribe, S., Ramirez, J., Pena, A. (1985), Effects of Beta-Pyrene on Yeast membrane functions. $J$. Bacteriol., 161, 1195-1200.
Uribe, S., Rangel, P., Espínola, G., Aguirre, G. (1990), Effects of cyclohexane, an industrial solvent, on the Yeast Saccharomyces cerevisiae and on isolated Yeast mitochondria. Appl. Environ. Microbiol., 56, 21142119.

Uygur, A. (2001), Reuse of decolourised wastewater of azo dyes containing dicholorotriazinyl reactive groups using an advanced oxidation method. Coloration Technol., 117, 111-113.

Valle, C. E. (1995), Qualidade ambiental: como ser competitivo protegendo o meio ambiente: (como se preparar para as normas ISO 14000). Pioneira, São Paulo, 137. 
PÁGINA

EM

BRANCO 